\title{
PENGARUH AROMATERAPI LEMON DAN GUIDED IMAGERY TERHADAP PENURUNAN SKALA NYERI PADA PASIEN DENGAN FRAKTUR EKSTREMITAS
}

\author{
The Effect of Lemon Aromatherapy and Guided Imagery on Reducing \\ Pain Scale in Patients with Extremity Fractures
}

\author{
Amir, Nirva Rantesigi* \\ ${ }^{1}$ Poltekkes Kemenkes Palu \\ *e-mail korespondensi: nirvarantesigi@gmail.com
}

\begin{abstract}
Abstrak
Pendahuluan : Fraktur adalah terputusnya kontinuitas tulang atau tulang rawan, baik yang bersifat total atau sebagian. Fraktur yang bersifat total apabila seluruh tulang patah sedangkan fraktur yang bersifat sebagian tidak melibatkan seluruh ketebalan tulang. Akibat yang muncul pada pasien fraktur umumnya akan merasakan nyeri. Rasa nyeri bisa timbul hampir pada setiap area fraktur, bila tidak diatasi akan menimbulkan efek yang membahayakan. Sehingga perlu penanganan yang terus menerus untuk meminimalkan nyeri yang dialami oleh pasien. Intervensi yang dapat digunakan untuk menangani nyeri fraktur adalah aromaterapi lemon dan guided imagery. Untuk mengetahui pengaruh penerapan Aromaterapi Lemon dan Guided Imagery terhadap penurunan skala nyeri pada pasien dengan fraktur ekstremitas di RSUD Poso. Metode : Metode yang digunakan dalam penelitian ini adalah metode penelitian kuantitatif dengan pendekatan Quasi-experimental dengan rancangan penelitian post test control group design. Jumlah sampel 30 orang dengan metode sampel purposive sampling. Hasil : Terdapat perbedaan rata-rata Skor nyeri sebelum dan setelah diberikan intervensi aromaterapi lemon \& guided imagery dengan p-value 0,005. Kesimpulan : Penggunaan aromaterapi lemon dan guided imagery dapat dijadikan salah satu intervensi mandiri perawat dalam penerapan asuhan keperawatan pada pasien dengan masalah nyeri
\end{abstract}

Kata Kunci: Nyeri; aromaterapi lemon; guided imagery.

\begin{abstract}
Introduction: A fracture is a break in the continuity of bone or cartilage, either totally or partially. Fractures are total if the entire bone is broken while partial fractures do not involve the entire thickness of the bone. As a result, fracture patients will generally feel pain. Pain can arise in almost any fracture area if not treated will cause harmful effects. So it needs continuous treatment to minimize the pain experienced by the patient. Interventions that can be used to treat fracture pain are lemon aromatherapy and guided imagery. To determine the effect of the application of Lemon Aromatherapy and Guided Imagery on reducing pain scale in patients with limb fractures at Poso Hospital. Methods: The method used in this study is a quantitative research method with a quasi-experimental approach with a post-test control group design research design. The number of samples is 30 people with the purposive sampling method. Results: There is a difference in the average pain score before and after being given the lemon aromatherapy \& guided imagery intervention with a pvalue of 0.005. Conclusion: The use of lemon aromatherapy and guided imagery can be used as a nurse's independent intervention in the application of nursing care to patients with pain problems
\end{abstract}

Keywords: pain; aromatherapy citrus; guided imagery.

https://doi.org/10.33860/mnj.v2i1.441

(C) 2021 by the authors. Submitted for possible open access publication under the terms and conditions of the Creative Commons Attribution (CC BY SA) license (https://creativecommons.org/licenses/by-sa/4.0/). 


\section{Pendahuluan}

Fraktur adalah terputusnya kontinuitas tulang atau tulang rawan, baik yang bersifat total atau sebagian ${ }^{1}$. Fraktur yang bersifat total apabila seluruh tulang patah sedangkan fraktur yang bersifat sebagian tidak melibatkan seluruh ketebalan tulang ${ }^{2}$. Akibat yang muncul pada pasien fraktur umumnya akan merasakan nyeri, selain itu pasien juga akan mengalamigangguan tidur, tidak mampu melakukan aktivitas, resiko terjadi infeksi, pembengkakan, serta berbagai masalah yang menggangu kebutuhan dasar ${ }^{3}$.

Penanganan untuk mengatasi nyeri dapat dibagi menjadi 2 bagian, yaitu manajemen farmakologi dan manajemen non farmakologi.Manajemen farmakologi yaitu pemberian obat yang mampu menghilangkan rasa nyeri. Sedangkan manajemen non farmakologi merupakan manajemen untuk menghilangkan rasa nyeri menggunakan teknik yaitu pemberian kompres dingin atau panas, aromaterapi, teknik relaksasi, terapi hypnothis, imajinasi terbimbing/guide imagery, terapi music dan massage ${ }^{3}$.

Salah satu teknik non farmakologi yaitu aromaterapi lemon. Aromaterapi lemon bermanfaat untuk memicu perubahan dalam sistem limbik, bagian dari otak yang berhubungan dengan memori dan emosi ${ }^{4}$. Mekanisme kerja aromaterapi dalam tubuh berlangsung melalui sirkulasi udara dan penciuman. Bau yang di hirup dari aromaterapi berhubungan dengan reseptor silia dan bau tersebut di pancarkan ke otak yang berkaitan dengan mood atau suasana hati ${ }^{5,3}$. Zat yang terkandung dalam lemon salah satunya adalah linalool yang berguna untuk menstabilkan system saraf sehingga dapat menimbulkan efek tenang. Hasil penelitian Narrilawati (2015) dan Rahmayati (2018), membuktikan aromaterapi lemon memiliki pengaruh dalam menurunkan tingkat nyeri pada pasien post operasi laparatomi.vSelain aromaterapi lemon, Guided imagery juga merupakan tehnik non farmakologi. Manfaat dari guided imagery yaitu sebagai intervensi perilaku untuk mengatasi kecemasan, stres dan nyeri ${ }^{6}$. Hal itu karena guided imagery dapat mengaktivasi sistem saraf parasimpatis.
Guide Imagery melibatkan alat indera visual, sentuhan, pendengaran, pengecap dan penciuman, dengan tujuan pasien menjadi lebih tenang dan rileks ${ }^{7}$. Hasil penelitian Astuti (2018), menunjukkan bahwa guide imagery dapat mengurangi nyeri pada pasien post operasi fraktur. Hasil penelitian Maharani (2017), guide imagery juga dapat mengurangi nyericpost rekonstruksi lumbal ${ }^{8}$.

Data yang diperoleh peneliti di Rumah Sakit Umum Poso, pada pengambilan data awal jumlah pasien yang mengalami Fraktur Ekstremitas pada tahun 2017 sebanyak 45 jiwa, pada tahun 2018 sebanyak 161 jiwa dan pada tahun 2019 sebanyak 127 jiwa. Hal ini menunjukan jumlah pasien yang mengalami fraktur ekstremitas dari tahun ketahun mengalami peningkatan ${ }^{9}$. Berdasarkan studi pendahuluan di Rumah Sakit Umum Daerah Poso, perawat lebih sering menggunakan teknik farmakologi dengan pemberian obatobatan medis dibandingkan teknik non farmakologi. Perawat belum memanfaatkan intervensi non farmakologi yang merupakan kompetensi seorang perawat, i9ntervensi non farmakologi juga dapat membantu pasien dalam mengurangi atau mengontrol nyeri tanpa efek samping. Penggunaan aromaterapi lemon dan guided imagery belum pernah di lakukan di Rumah Sakit Umum Daerah Poso untuk mengurangi atau mengontrol nyeri. Berdasarkan fenomena tersebut, maka dari itu penulis tertarik untuk melakukan studi kasus tentang "Pengaruh Aromaterapi Lemon dan Guided Imagery Terhadap Penurunan Skala Nyeri Pada Pasien Dengan fraktur Ekstremitas Di RSUD Poso"

\section{Metode}

Metode yang digunakan dalam penelitian ini adalah metode penelitian kuantitatif dengan pendekatan Quasi-experimental dengan rancangan pre post test control group design. Penelitian ini terdiri dari 3 kelompok yaitu kelompok yang mendapat perlakuan aromaterapi lemon, kelompok yang mendapat perlakuan aromaterapi lemon dan guided imagery, dan kelompok yang mendapatkan perawatan standar. 
Pemberian aromaterapi lemon dalam penelitian ini dengan menggunakan diffuser sebanyak 5 tetes dalam $50 \mathrm{ml}$ air hangat yang diberikan selama 30 menit, sedangkan guided imagery merupakan imajinasi terbimbing yang berisi nada instrument dan suara alam diberikan dengan menggunakan earphone sambal pasien melakukan relaksasi napas selama 15 menit. Penelitian ini dilaksanakan di Rumah Sakit Umum Daerah Poso pada bulan Juli - Oktober 2019. Populasi dalam penelitian ini adalah semua pasien fraktur yang dirawat diruang bedah. Sampel dalam penelitian ini adalah pasien dengan fraktur ektremitas sebanyak 30 orang. Pengambilan sampel dengan cara purposive sampling. Instrument penelitian adalah lembar obeservasi nyeri meliputi penilaian level nyeri menggunakan Numeric Rating Scale (NRS) dan karakteristik responden.

\section{Hasil Penelitian}

Pada tahap ini dilakukan analisis univariat karakteristik responden berdasarkan faktor demografi terdiri dari umur, jenis kelamin, pekerjaan dan lama hari rawat.

Tabel 1 Distribusi Frekuensi Berdasarkan Umur, jenis kelamin, pekerjaan dan lama hari rawat

\begin{tabular}{llcc}
\hline Karakteristik & \multicolumn{1}{c}{ Kategori } & n & \% \\
\hline Umur & < 20 Tahun & 6 & 20 \\
& 21 - 30 Tahun & 8 & 26,7 \\
& 31-40 Tahun & 5 & 16,7 \\
& 41 -50 tahun & 4 & 13,3 \\
& $>$ 50 Tahun & 7 & 23,3 \\
\hline Jenis Kelamin & Laki-laki & 24 & 80 \\
& Perempuan & 6 & 20 \\
\hline Pekerjaan & Tani & 3 & 10 \\
& Wiraswasta & 19 & 63,3 \\
& PNS & 4 & 13,3 \\
& Pelajar & 3 & 10 \\
& IRT & 1 & 3,3 \\
\hline Lama Rawat & 1 hari & 3 & 10 \\
& 2 hari & 4 & 13,3 \\
& 3 hari & 11 & 36,7 \\
& 4 hari & 5 & 16,7 \\
& 5 hari & 4 & 13,3 \\
& 6 hari & 2 & 6,7 \\
& 7 hari & 1 & 3,3 \\
\hline
\end{tabular}

Berdasarkan tabel 1 menunjukkan bahwa dari 30 orang responden, kelompok umur terbanyak berusia 21-30 tahun sebanyak 8 orang (26,7\%), jenis kelamin laki-laki sebanyak 24 orang
$(80 \%)$, jenis pekerjaan wiraswata sebanyak 19 orang $(63,3 \%)$ dan lama hari rawat selama 3 hari sebanyak $(36,7 \%)$

Perbedaan rerata skor nyeri antara kelompok aromaterapi lemon, aromaterapi lemon dan guide imagery dan perawatan standar

Tabel 2 Rerata perbedaan skor nyeri sebelum dan setelah intervensi

\begin{tabular}{lccc}
\hline Pengukuran & $\begin{array}{c}\text { Aromate } \\
\text { rapi } \\
\text { lemon }\end{array}$ & $\begin{array}{c}\text { Aromaterapi } \\
\text { lemon \& } \\
\text { guide } \\
\text { imagery }\end{array}$ & $\begin{array}{l}\text { Perawatan } \\
\text { Standar }\end{array}$ \\
\hline $\begin{array}{l}\text { Sebelum } \\
\text { perlakuan }\end{array}$ & 6.60 & 7.20 & 6.70 \\
\hline $\begin{array}{l}\text { Setelah } \\
\text { perlakuan }\end{array}$ & 6.00 & 2.40 & 6.70 \\
\hline$p$-value & 0.034 & 0.005 & 1.000 \\
\hline
\end{tabular}

Berdasarkan tabel 2 menunjukkan bahwa mean ranking kelompok aromaterapi lemon dan aromaterapi lemon \& guide imagery samasama mengalami penurunan skor nyeri pada pengukuran hari ke 14. Hasil uji Wilcoxon pada kelompok aromaterapi lemon dan aromaterapi lemon \& guide imagery menunjukkan nilai $\mathrm{p}<0,05$. Maka dapat disimpulkan ada perbedaan rata-rata yang signifikan antara kelompok aromaterapi lemon dan aromaterapi lemon \& guide imagery pada pengukuran skor nyeri sebelum perlakuan dan setelah perlakuan.

\section{Pembahasan}

Berdasarkan hasil analisa yang telah dilakukan pada pasien fraktur di Ruang Rawat Inap Bedah RSUD Poso didapatkan bahwa responden terbanyak berusia 21-30 tahun yaitu 8 responden $(26,7 \%)$. Menurut Smeltzer dan Bare, (2013) diperkirakan 85\% usia produktif sedikitnya mempunyai satu masalah kesehatan kronis yang dapat menyebabkan nyeri, usia merupakan variabel penting yang mempengaruhi nyeri ${ }^{10}$. Perbedaan perkembangan, yang ditemukan di antara kelompok usia ini dapat mempengaruhi cara beraeaksi terhadap nyeri, misalnya anak anak dan lansia.

Hal ini berkaitan dengan penelitian Hekmatpou et al (2017) menunjukkan bahwa responden 
yang mengalami nyeri paling banyak berusia dewasa yaitu usia antara 20-29 tahun ${ }^{11}$. Hal ini juga sesuai dengan hasil penelitian dimana Menunjukkan ada hubungan umur (pvalue $=0,014)$, jenis kelamin $(p-$ value $=0,011)$, dengan respon nyeri pasien post operasi mayor $^{12}$. Pada umur lansia pasien lebih siap melakukan, menerima dampak, efek dan komplikasi tindakan operasi dari pada dewasa. Dalam umur seseorang belum tentu dapat menahan dan menerima suatu tindakan dalam dirinya yang dapat menimbulkan kecacatan pada dirinya. Menurut asumsi peneliti usia dewasa lebih merasakan nyeri daripada lansia hal ini dikarenakan lansia cenderung untuk mengabaikan nyeri dan menahan nyeri yang berat dalam waktu yang lama sebelum melaporkannya atau mencari perawatan kesehatan ${ }^{10}$.

Secara umum pria dan wanita tidak berbeda secara bermakna dalam berespon terhadap nyeri. Dalam penelitian ini peneliti membagi kelompok usia responden laki-laki dan perempuan menjadi 2 kelompok yaitu kelompok dewasa dan kelompok lansia. Data yang diperoleh peneliti, responden laki-laki dan perempuan tidak memiliki proporsi yang sama, responden laki-laki lebih banyak yang mengalami nyeri dari pada responden perempuan. Namun, skor nyeri responden laki laki lebih tinggi dari pada responden perempuan ${ }^{13}$. Menurut Wijaya (2014) intensitas nyeri pasien fraktur pada laki-laki lebih tinggi daripada wanita dengan $p$-value $=0,004^{14}$. Menurut asumsi peneliti laki-laki lebih responsif terhadap nyeri dari pada perempuan. Perempuan lebih banyak memiliki pengalaman nyeri dari pada laki-laki. Dalam penelitian ini usia perempuan berada pada rentang usia dewasa sehingga kemungkinan sudah pernah melahirkan dan pernah merasakan nyeri yang berat sebelumnya ${ }^{14}$.

Keluhan nyeri adalah hal yang paling sering muncul setelah pembedahan. Hasil penelitian ini menunjukkan bahwa tidak ada responden yang tidak mengalami nyeri. Faktor yang dapat menyebabkan nilai nyeri berbeda-beda atau bervariasi dan menunjukan perubahan yang relatif kecil, dan reaksi terhadap nyeri dipengaruhi oleh berbagai faktor, seperti usia, jenis kelamin, latar belakang sosial budaya, lingkungan, dan pengalaman sensori itu sendiri.
Arti nyeri bagi seseorang memiliki banyak perbedaan dan hampir sebagian arti nyeri merupakan arti yang negatif, seperti membahayakan merusak dan lain-lain. Pemberian aromaterapi menjadi salah satu alternatif terapi bagi mereka yang sedang mengalami tekanan batin atau stres, dan yang paling penting yaitu untuk menurunkan intensitas nyeri ${ }^{15}$. Menurut asumsi peneliti penurunan nyeri yang dialami oleh responden disebabkan oleh pemberian terapi non farmakologi yaitu aromaterapi lemon karena didalam aromaterapi lemon tersebut terdapat zat-zat yang dapat membuat responden menjadi rileks dan tenang, sehingga nyeri yang dirasakan tersebut dapat berkurang. Hasil penelitian menunjukkan bahwa terdapat perbedaan skor nyeri pada pasien fraktur sebelum dan setelah diberikan intervensi aromaterapi lemon dengan $\mathrm{p}$-value 0,034 .

Guided imagery adalah metode relaksasi untuk mengkhayalkan tempat dan kejadian berhubungan dengan rasa relaksasi yang menyenangkan. Guided imagery mempunyai elemen yang secara umum sama dengan relaksasi, yaitu sama-sama membawa klien kearah relaksasi. Guided imagery menekankan bahwa klien membayangkan hal-hal yang nyaman dan menenangkan. Penggunaan guided imagery tidak dapat memusatkan perhatian pada banyak hal dalam satu waktu oleh karena itu klien harus membayangkan satu imajinasi yang sangat kuat dan menyenangkan ${ }^{16}$. Guided imagery merupakan imajinasi yang dirancang secara khusus untuk mencapai efek positif. Dengan membayangkan hal-hal yang menyenangkan maka akan terjadi perubahan aktifitas motorik sehingga otot-otot yang tegang menjadi relaks, respon terhadap bayangan menjadi semakin jelas. Hal tersebut terjadi karena rangsangan imajinasi berupa halhal yang menyenangkan akan dijalankan kebatang otak menuju sensor thalamus untuk diformat. Sebagian kecil rangsangan itu ditransmisikan ke amigdala dan hipokampus, sebagian lagi dikirim ke korteks serebi. Sehingga pada korteks serebi akan terjadi asosiasi pengindraan. Pada hipokampus hal-hal yang menyenangkan akan diproses menjadi sebuah memori. Ketika terdapat rangsangan berupa imajinasi yang menyenangkan memori yang tersimpan akan muncul kembali dan menimbulkan suatu persepsi. Dari hipokampus 
rangsangan yang telah mempunyai makna dikirim ke amigdala yang akan membentuk pola respon yang sesuai dengan makna rangsangan yang diterima. Sehingga subjek akan lebih mudah untuk mengasosiasikan dirinya dalam menurunkan sensasi nyeri yang di alami. Hasil penelitian menunjukkan bahwa pada kelompok aromaterapi lemon \& guided imagery terjadi perbedaan skor nyeri sebelum dan setelah diberikan intervensi dengan menggunakan uji Wilcoxon signed rank test $\mathrm{p}$ value 0,005 .

Menurut asumsi peneliti hal tersebut bisa dijelaskan melalui konsep pengkondisian klasik berupa imajinasi tentang pengalaman yang menyenangkan, sehingga menimbulkan reaksi terhadap stimulus. Ketika individu mengalami nyeri maka respon yang muncul adalah sensasi nyeri. Tetapi ketika individu mengalami nyeri dan stimulus yang dimunculkan adalah perasaan menyenangkan maka reaksi yang muncul adalah perasaan senang. Sehingga lama kelamaan dengan memberikan stimulus perasaan yang menyenangkan rasa nyeri akan berangsur-angsur menghilang dan tergantikan menjadi perasaan senang.

\section{Kesimpulan}

Kombinasi Aromaterapi lemon dan guided imagery efektif menurunkan nyeri pada pasien fraktur. Penggunaan aromaterapi lemon dan guided imagery dapat dijadikan salah satu intervensi mandiri perawat dalam penerapan asuhan keperawatan pada pasien dengan masalah nyeri

\section{Ucapan Terima Kasih}

Penulis mengucapkan terima kasih kepada semua pihak yang telah berkontribusi dalam penelitian ini sehingga bias terlaksana dengan baik

\section{Daftar Pustaka}

1. Agustina. Asuhan Keperawatan Pada Ny.D dengan Prioritas Masalah Kebutuhan Dasar Rasa Nyaman: Nyeri pada Pasien Post Operasi Fraktur Tibia 1/3 Proximal dextra di RSUD. Dr. Pirngadi Medan [Internet]. 2017 [cited 2019 Apr 8]. Available from: http://repositori.usu.ac.id/handle/1234567 $89 / 2721$

2. Guyton, A. C, Hall JE. Buku Ajar Fisiologi Kedokteran. 12th ed. Jakarta: EGC; 2014.

3. Mandagi CAF, Hamel RS, Bidjuni $\mathrm{H}$. Karakteristik Yang Berhubungan Dengan Tingkat Nyeri Pada Pasien Fraktur Di Ruang Bedah Rumah Sakit Umum Gmim Bethesda Tomohon. e-journal Keperawatan. 2017;5(1).

4. Rahmayati E, Hardiansyah R, Nurhayati N. Pengaruh Aromaterapi Lemon terhadap Penurunan Skala Nyeri Pasien Post Operasi Laparatomi. J Kesehat. 2018;9(3):427.

5. Nurjannah R. Pemberian Aromaterapi Lemon Terhadap Penurunan Skala Nyeri Pada Asuhan Keperawatan Post Operasi Laparatomi [Internet]. 2019. Available from:

http://repository.itspku.ac.id/id/eprint/155

6. Astuti ND, Respati CA. Pengaruh Terapi Guided Imagery Terhadap Nyeri Pada Pasien Post Operasi Fraktur Di Ruang Bougenvil RSUD Dr. R. Koesma Tuban. J Midpro [Internet]. 2018 Dec 1;10(2):52. Available from: http://jurnalkesehatan.unisla.ac.id/index.ph p/midpro/article/view/81

7. Potter PA, Perry AG. Fundamental Of Nursing. 7th ed. Jakarta: EGC; 2011.

8. Febtrina R, Febriana W. Teknik Relaksasi Imajinasi Terbimbing ( Guided Imagery ) Menurunkan Nyeri Pasien Pasca Serangan Jantung. Nurs Curr. 2017;5(2):41-9.

9. Rumah Sakit Umum Daerah Poso. Jumlah Pasien Fraktur Yang dirawat di Ruang Bedah RSUD Poso Tahun 2019. Poso; 2019.

10. Smeltzer S, Bare B. Keperawatan Medikal Bedah. 8th ed. Jakarta: EGC; 2013.

11. Hekmatpou D, Pourandish Y, Farahani P, Parvizrad R. The effect of aromatherapy with the essential oil of orange on pain and vital signs of patients with fractured limbs admitted to the emergency ward: A randomized clinical trial. Indian $\mathbf{J}$ Palliat Care [Internet]. 2017;23(4):431. Available from: http://www.jpalliativecare.com/text.asp?2 
017/23/4/431/216093

12. Apóstolo JLA, Kolcaba K. The Effects of Guided Imagery on Comfort, Depression, Anxiety, and Stress of Psychiatric Inpatients with Depressive Disorders. Arch Psychiatr Nurs [Internet]. 2009 Dec;23(6):403-11. Available from: https://linkinghub.elsevier.com/retrieve/pii /S0883941708002045

13. Potter PA, Perry AG. Fundamental Of Nursing: Consept, Proses and Practice. 7th ed. Jakarta: EGC; 2010.

14. Wijaya IPA, Evi Yantini K, Susila IMDP. Faktor-Faktor yang Memengaruhi Intensitas Nyeri Pasien Pasca Operasi Fraktur Ekstremitas Bawah di BRSU Tabanan. J Cent Res Publ Midwifery Nurs [Internet]. 2018 Jun 28;2(1). Available from:

http://ejournal.binausadabali.ac.id/index.p $\mathrm{hp} /$ caring/article/view/28

15. Koensoemardiyah. A-Z Aromatherapy untuk Kesehatan, Kecantikan, dan Kebugaran. Yogyakarta: Andi Press; 2009.

16. Linda B, Jess F. Health psychology: an introduction to behavior and health [Internet]. United State Of America; 2010. Available from: Matrix Production Inc 